\title{
Shared teaching with multimedia-enhanced video-conferencing
}

\author{
Charles Duncan,* Martin Morrey,* Gwen Bayne,** lain MacLaren,**** \\ Patrick Walder,*** John McQuillan**** \\ *Department of Meteorology, University of Edinburgh \\ **Department of APEME, University of Dundee \\ ****Department of Electronic Engineering and Physics, University of Paisley
}

Video-conferencing was used to share a short series of lectures between several universities. A high bandwidth network (155Mbit/s) permitted near broadcast TV quality video to be combined with fully mixed, high-quality audio. The lectures were supported by visual aids made available using Microsoft NetMeeting to provide multipoint, shared applications. NetMeeting is shown to be a stable and effective platform for distributing multimedia material at a much higher resolution than is possible using the video signals common in most video-conference lectures, although care must be taken when constructing animated material.

\section{Introduction}

In Scotland all 13 universities and a number (8) of other related institutions of higher education are connected on a high bandwidth computer network. Organizationally, this is composed of four interconnected Metropolitan Area Networks (MANs). The high bandwidth (155 Mbit/s) and the network's operation under ATM (Asynchronous Transfer Mode) enables routine use of high quality video-conferencing between institutions. Each institution has at least one (all the universities have two) video-conferencing suites, fully equipped with audio and video equipment and direct network access for PCs.

This unique national infrastructure is being exploited by a number of projects that are supported by the Scottish Higher Education Funding Council's (SHEFC) Use of MANs Initiative (UMI) (see, for example, Lindsay and Grant, 1998). One such project, the National Learning Network for Remote Sensing (MacLaren, Duncan and Vaughan, 1997), is making extensive use of the network to produce, deliver and evaluate Web-based learning materials, virtual laboratories and a programme of shared lectures and seminars. This project is a collaboration between the Universities of Paisley, Edinburgh and Dundee 
and a wider consortium with membership from several other institutions. The principal aim is to improve the learning experience of students across Scotland studying remote sensing as a specialism within degrees in subjects such as geography, environmental science, physics and engineering. Sharing of resources and expertise, both in research and teaching, it is hoped, will improve student understanding and strengthen the somewhat dispersed remote sensing community. The materials being developed are at senior undergraduate and postgraduate level and the total number of students studying remote sensing in any given academic year is approximately $150-200$.

In this paper we present details of our initial experiments in the use of video-conferenced lectures in actual courses and make a number of recommendations from both technical and pedagogical standpoints for the future use of such a medium. Evaluation and user feedback are key aspects of our project and it is due to the conscientious efforts of the students on these courses in responding to questionnaires and interviews that we have been able to learn so much.

The recent growth in the use of video-conferencing studios as electronic classrooms (Pedersen, 1996; BIC, 1997) and in developing Metropolitan Area Networks to support video-conferencing has led to various studies of implementation strategies (see, for example several reports by SIMA (Support Initiative for Multimedia Applications)) and pedagogical design issues (Donert, Brady and Clarkson, 1998). In virtually all of these cases the audio-visual material used in teaching is transmitted using the same video technology as the video conference, that is, it is encoded at PAL (or lower) resolution and transmitted using a codec which involves compression and some loss of signal quality. This quality of visual presentation is adequate for some teaching applications, but is inadequate for the computer-aided presentations which are now common. The video signal is incapable of supporting current resolutions, commonly $800 \times 600$ and occasionally higher. In our lectures we used the MANs to support shared applications between computers to enable high-resolution displays to be used in a multi-point video-conference.

\section{Video-conference lecture programme}

For several years, a lecturer from the University of Edinburgh has given a short series of three lectures on a rather specialist topic (Synthetic Aperture Radar) to groups of students in both his own institution and Heriot-Watt University (also in Edinburgh). However, this topic also features in courses in the Universities of Paisley and Dundee and therefore it was realized that this might form an excellent candidate for the use of video-conferencing. The small number of lectures might not seem to be appropriate for conclusive statistical analyses, but in fact it did have a distinct advantage in that we were experimenting with a new form of communication and teaching (to the students, at least) in the midst of formal, examinable taught courses. Before a larger fraction of a course could be delivered by such means, we required detailed evaluation of relevant technical and educational issues to ensure that students' learning (and examination performance!) was not being placed 'at risk' by presupposing a favourable response.

For this exercise, the lectures were presented from Edinburgh University and shared with ten final-year physics students at Heriot-Watt University, six final-year physics students at Paisley University, and eight students taking an M.Sc. in Remote Sensing based at Dundee 
University. For the students at Heriot-Watt and Paisley these lectures were a compulsory part of their course and the material covered was examinable in their finals. The arrangement for the Dundee students was that these lectures were a voluntary (but recommended) supplement to their existing course.

Offering lectures via this medium poses a number of challenges. For example, the arrangement in a typical video-conferencing suite is such that the participants are faced with two TV monitors, one displaying the outgoing picture from that studio and the other displaying the incoming signal (Figure 1).

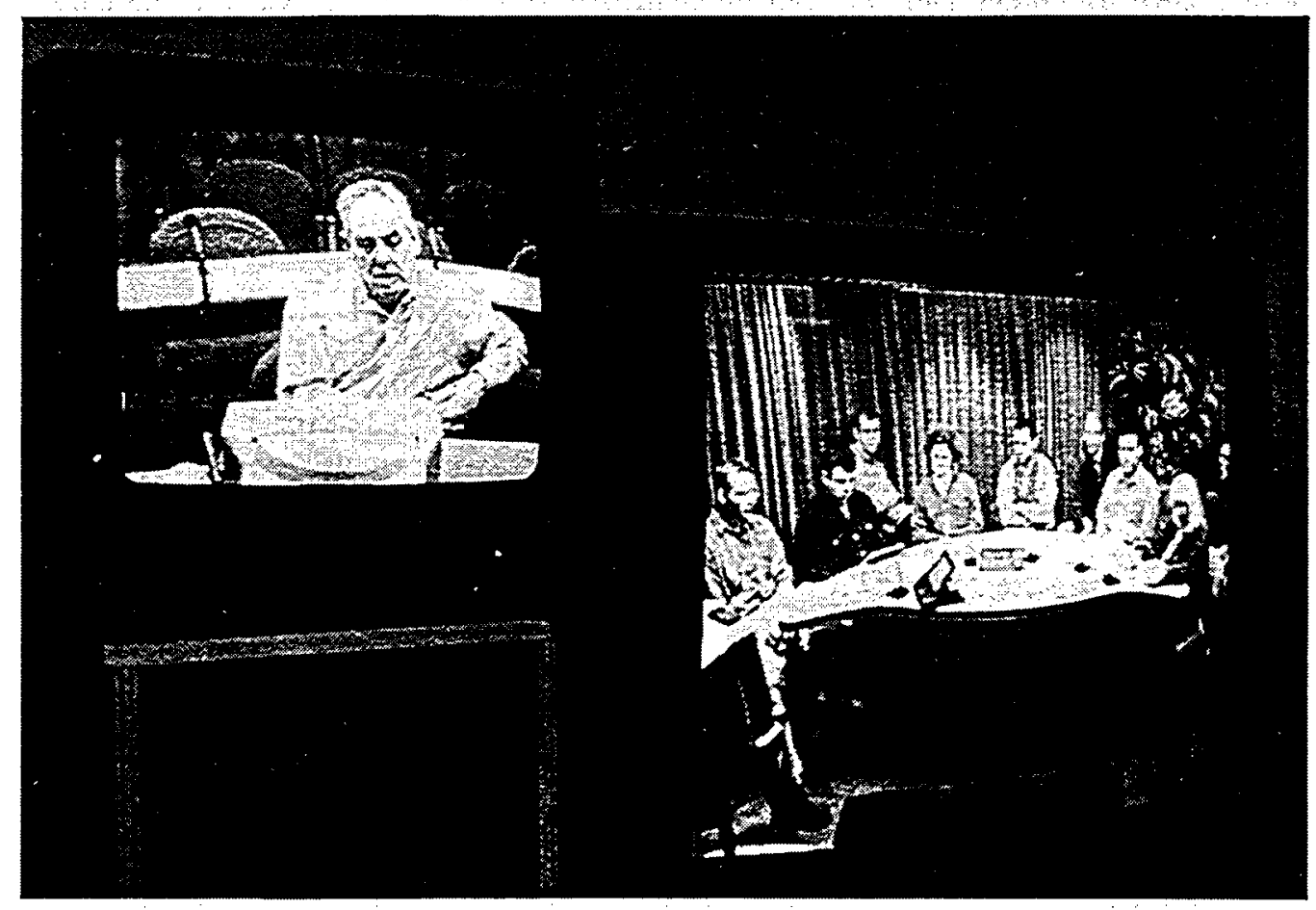

Figure 1:Two monitors in the Edinburgh studio showing (left) the outgoing signal and (right) the incoming signal from Dundee since students there had just responded to a question.

In addition a desktop 'visualizer' enables the participants to present paper-based materials, transparencies, slides and indeed small objects. The presenter can switch between the main studio camera and this visualizer. In a subject such as remote sensing, however, it is often important to be able to present high-quality digital images and even illustrative animations that help explain complex issues such as orbits, scanning, etc. In recent years a number of lecturers have been making limited but increasing use of presentation technologies such as PowerPoint displays on data projectors and LCD panels in their classes. To use such materials in the course of a video-conferenced lecture would typically mean converting the appropriate computer display output to a lower quality PAL signal. After a number of initial experiments we were led to the conclusion that the loss of quality was such that we required an alternative approach. In addition, were the signal to be passed through the main video- 
conferencing display the students would lose 'face-to-face' contact with the lecturer whilst the slides, images and animations were being presented.

Our approach to this problem exploited the existing network connections in each videoconferencing suite and is described in detail in the next section.

\section{Enhancing video-conferences with multimedia materials}

The intention, then, is to be able to display high-quality graphics and PowerPoint presentations at all participating sites whilst simultaneously allowing the participants to view the lecturer. Ideally, the PowerPoint slides and graphics should, of course be under the control of the remote lecturer so that the presentations at all locations were synchronized and individual slides could be revisited or skipped if necessary. The only available tool we were able to identify that was capable of this was Microsoft NetMeeting.

Microsoft NetMeeting (2.1) is a software tool for linking several Windows (95/NT) PCs in a conference session to enable communication and collaboration (Microsoft, 1998). Up to 32 participants in a 'NetMeeting' can join a common chat session and share control of the built-in whiteboard. Two participants at a time can speak to each other using the audio facility, and see each other if their machines have suitable video equipment. A very useful facility allows an application running on one of the machines in the meeting to be 'shared' with all the others. This application can take up the whole screen, allowing one participant to control the displays on all the other machines in the meeting. In 'collaborate' mode, control of this application can be passed to another participant at any remote site. Microsoft NetMeeting can be downloaded freely from the Microsoft web-site, www.microsoft.com.

This approach required that all the video-conferencing suites involved had an ethernet connection, a Windows 95/NT PC, and a data-projector or large monitor. Network support at some sites questioned the wisdom of using noisy data-projectors in relatively small rooms, with sensitive microphones using preset switching thresholds, but in the event this did not prove a significant problem.

\section{Rehearsals and tests}

Prior to the actual lecture series a number of trials were undertaken to determine the optimum configuration of the hardware and software for our specific needs. Whilst NetMeeting is used extensively for informal communication by individuals and organizations, its deployment in our project required a number of specific technical issues to be addressed. These are listed as follows.

How can we be sure that the displays are synchronized and we can rely on everyone seeing the same display at all times?

To test the response time, the video-conferencing system was used to relay the display back to the originating site by simply pointing a video camera at the computer screen. The quality was degraded but it was easy to see screen changes. In all cases the remote displays changed within one second of the originating display. 
Would the synchronization allow PowerPoint animations to be adequately represented? A simple test using PowerPoint with 'flying' bullet points showed that all frames are not transmitted to the remote display. A 'flying' bullet point might only appear once at the edge of the screen and then in its final destination. Sometimes it would only appear in its final destination so that the animated effect was completely missed at the remote site. This revealed that animations must be quite slow to be viewed remotely and that a better approach, used successfully during these lectures, is to create an animated effect by building a diagram from many components. The display of each subsequent component can then be controlled by a mouse click on the originating machine. The build-up is slow but nevertheless it should add to the student's understanding. One example of the use of this technique was the propagation of a wave front and its interaction with several objects (Figure 2).

\section{Operation}

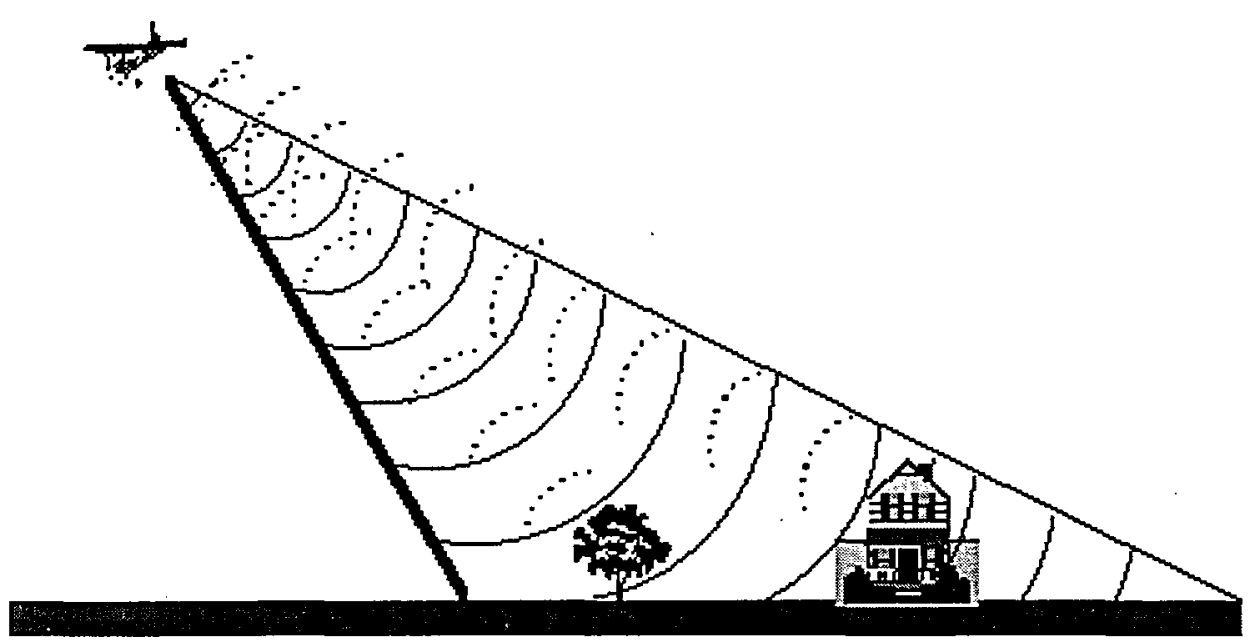

Figure 2: Example PowerPoint slide containing 'animated' wavefront sequence.

Is it better to use an ILS (Internet) or direct IP (Internet Protocol) connections?

Microsoft and others provide directory servers, which allow NetMeeting users to find each other by name or email address. However these servers are based in the USA, and are quite heavily used, so using them in the UK can cause delays, especially in the afternoon. We therefore required that each participating PC placed a direct call to the IP address of the 'host' machine (i.e. the PC at the lecturer's site).

Direct IP connections were found to be faster and worked satisfactorily even when the originating machine was a $33 \mathrm{MHz} 486$. In practice, however, we used a Pentium 166 with $32 \mathrm{Mb}$ RAM for the lecture series since a higher specification did give improved 


\begin{tabular}{|c|c|c|c|c|}
\hline Media type & Examples of organizing the structure & $\begin{array}{l}\text { New } \\
\text { (hours) }\end{array}$ & $\begin{array}{l}\text { Existing } \\
\text { (hours) }\end{array}$ & Resources required \\
\hline Asynchronous bulletin board & Set up forums and write activities & $2-5$ & 0 & BB Software \\
\hline Audio-vision & Prepare script and record, write handout & $50-200$ & $5-20$ & Recording equipment, script \\
\hline Audio-cassette & Prepare script and record & $20-100$ & $2-10$ & Recording equipment script \\
\hline Broadcast TV & Prepare script and record & $50-500$ & $5-20$ & Recording equipment, script \\
\hline Email & Define use & $0-1$ & 0 & Email sofware \\
\hline Fill in the gaps & Design and word process fill in the gaps & $5-20$ & $1-5$ & - \\
\hline Hypertext & Produce HTML documents and gifs & $2-10$ & $5-20$ & HTML editor, browser \\
\hline Mieroworlds & $\begin{array}{l}\text { Author microworid or provide } \\
\text { accompanying explanations }\end{array}$ & $5-200$ & $5-20$ & $\begin{array}{l}\text { MMPC. microworld software, } \\
\text { authoring software }\end{array}$ \\
\hline Multimedia & Author material and record clips & $100-200$ & $\begin{array}{l}5-20 \\
\text { audio) }\end{array}$ & $\begin{array}{l}\text { MMPC, Multimedia software } \\
\text { (authoring, graphics, and }\end{array}$ \\
\hline Radio & Prepare script and record & $20-100$ & $2-10^{-}$ & Broadcasting equipment. seript \\
\hline SAQs & Author questions & $5-20$ & $2-5$ & Assessment software \\
\hline Simulations & $\begin{array}{l}\text { Author simulation or set the scene for } \\
\text { the exercise }\end{array}$ & $5-100$ & $5-20$ & $\begin{array}{l}\text { MMPC, simulation software, } \\
\text { authoring software }\end{array}$ \\
\hline $\begin{array}{l}\text { Synchronous audio } \\
\text { conferencing }\end{array}$ & Set the scene & $2-3$ & 0 & $\begin{array}{l}\text { Broadcasting and reception } \\
\text { equipment and/or software }\end{array}$ \\
\hline Synchronous chat systerns & Write instructions and define use & $0-1$ & 0 & Chat software \\
\hline $\begin{array}{l}\text { Symchronous, video } \\
\text { conferencing }\end{array}$ & Set the scene or prepare "lecture" & $2-5$ & 0 & $\begin{array}{l}\text { Broadcasting and reception } \\
\text { equipment and/or software }\end{array}$ \\
\hline Tutorial Program & Author program or provide instructions & $20-100$ & $5-20$ & $\begin{array}{l}\text { MMPC, turtoring software, } \\
\text { authoring software }\end{array}$ \\
\hline Tutorial Simulation & Author program or provide instructions & $75-300$ & $5-20$ & $\begin{array}{l}\text { MMPC, tutoring software. } \\
\text { authoring software }\end{array}$ \\
\hline Tutorial System & Author program or provide instuctions & $50-200$ & $5-20$ & $\begin{array}{l}\text { MMPC, tutoring software, } \\
\text { authoring software }\end{array}$ \\
\hline Video-cassette & Prepare script and record & $50-200$ & $5-20$ & Recording equipment, script \\
\hline Whiteboards & Prepare instructions for use & $1-2$ & 0 & Whiteboard software \\
\hline Fieldtrips & Prepare activities, arrange bookings & $5-20$ & 0 & $\begin{array}{l}\text { Transport, location, } \\
\text { accommodation }\end{array}$ \\
\hline Formal exam & Word Process, Exam boards & $10-15$ & 0 & - \\
\hline Lecture & $\begin{array}{l}\text { Organize notes write OHPs or } \\
\text { slide presentations }\end{array}$ & $2-5$ & 0 & $\begin{array}{l}\text { Overheads, presentation } \\
\text { software }\end{array}$ \\
\hline Practicals & $\begin{array}{l}\text { Design and test experiments, } \\
\text { Write manual, Order materials }\end{array}$ & $10-20$ & 0 & Lab, equipment materials \\
\hline Print (handouts or workbooks) & Word process material & $5-20$ & $1-5$ & - \\
\hline Progress tests & Word process & $2-5$ & 0 & - \\
\hline Seminar & Set seminar topic & $0-3$ & 0 & - \\
\hline Tutorial - S/S & Setting the scene for student-led tutorial & $0-1$ & 0 & - \\
\hline Tutorial - T/S & Prepare tutorial sheet & $2-5$ & 0 & - \\
\hline
\end{tabular}

Table 1: Preparatory work comparison chart

grading. This grading rates media uses from 0 (rarely if ever supports this interaction) to 3 (this interaction is central). This provides a much finer analysis of the strengths and weaknesses of resources, providing a clearer picture of the educational benefits of different media uses.

As with the preparation work table (Table 1), it is proposed that this be worked through by practitioners involved in embedding C\&IT. This ensures that the system accurately reflects individuals' teaching styles, and avoids being prescriptive. The results shown in the tables 


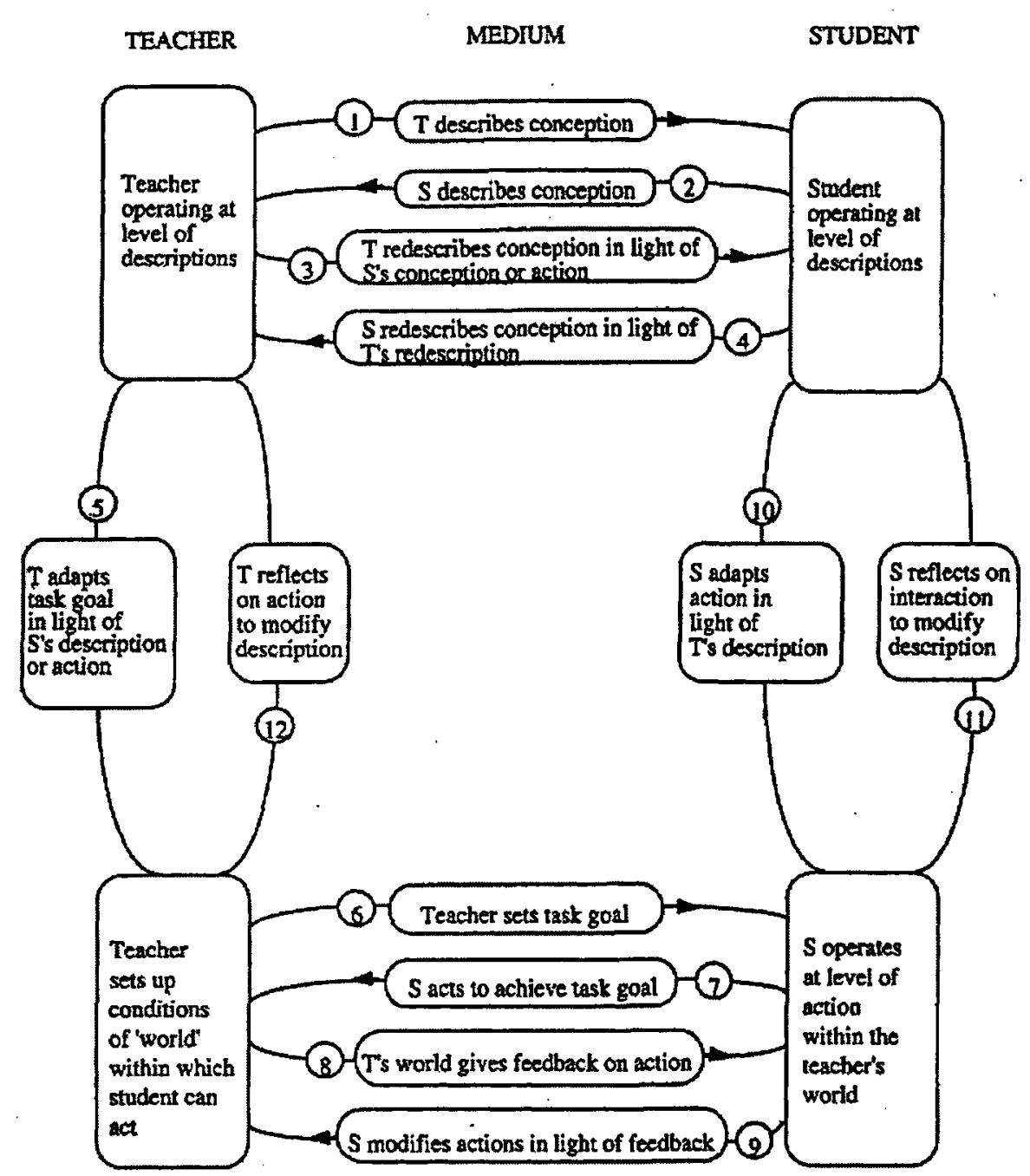

Figure I: Laurillard's conversational framework

have been collated from tables completed by the same five subjects who completed Table 1 , and are again intended to be illustrative rather than definitive. In the tables, the numbers 1 to 3 are replaced by asterisks.

Table 2 presents the interactions for traditional learning situations, such as lectures and tutorials, and Table 3 repeats this process for computer-based media. Worth noting are the low scores assigned to tutor reflection on many of the computer-based media. This reflects a worry that tutors who rely on these in place of face-to-face teaching may lose track of students' progress.

The scores also stress the value of traditional teaching using tutorials and seminars. This complements research which shows what students enjoy most is small group tutorials, and 
feedback questionnaire. The three questionnaires were tailored specifically to each videoconference (VC) and the questions varied. The ability to see how attitudes changed, was affected somewhat by the fact that different numbers of students attended each session with the numbers ranging from 24 at the first video-conference (VC1) to 15 at VC2 and 9 at VC3 (see Table 1).

\begin{tabular}{lccc}
\hline & VCI & VC2 & VC3 \\
\hline Dundee & 8 & 7 & - \\
Paisley & 6 & 4 & 5 \\
Heriot-Watt & 10 & 7 & 4 \\
Total & 24 & 15 & 9 \\
\hline
\end{tabular}

Table 1: Numbers of students atterding the three video-conference lectures

This fall-off in attendance is not as telling as it may first seem however, since the Dundee students had a prior commitment on the day of the third lecture. Instead, the only noticeable fall-off in attendance was from the Heriot-Watt students.

As well as being asked specific questions, in each questionnaire, students were encouraged to write any comments they had. Most comments came after the first (and best attended) video-conference. All students who attended completed the questionnaires.

\section{Expectations}

Of the 24 students attending $\mathrm{VCl}$, only 4 had attended a video-conference before. It was encouraging then, that 83.3 per cent of these students indicated that the experience was less confusing than they had expected, with only 12.5 per cent saying it was more so (the remainder found it the same as expected).

\section{Questions}

A total of 62.5 per cent of the students attending $\mathrm{VCl}$ felt 'more remote from the lecturer than in a traditional lecture' ( 20.8 per cent felt less remote and 16.7 per cent felt the same). These results may indicate a serious disadvantage of video-conferencing in that the interactive element of lecturing was lost. One student did comment 'you can not talk to the teacher personally'. However, the students felt more able to ask questions as the lectures went on. In the first lecture students were asked if they felt more or less able to ask questions than in a conventional lecture. Of the 24 students attending, 20 answered that they felt less able to ask questions, while the remainder said they felt the same as in a normal lecture. At each of the subsequent lectures they were asked if they now felt more able to answer questions. At the second lecture seven now felt more able to ask questions than at the first lecture while seven still felt inhibited. At the third lecture a further four students said they now felt more able to ask questions than they had in the second lecture.

It should be noted, that despite this improvement, no unprompted questions were asked throughout the series of lectures. However, it is common that very few questions are asked during technical lectures and the reticence to ask questions may not be significant since the 
main reason given for not asking questions was that they 'simply couldn't think of anything to ask'. This was the response for 73.3 per cent at VC2 and 66.7 per cent at VC3.

\section{Enjoyment}

At VC1, 41.7 per cent of students indicated that they enjoyed this method of teaching more than their normal lectures, but the same proportion enjoyed it less. The remaining 16.6 per cent of students enjoyed it the same amount or made no response. However, two students noted that they enjoyed it more only because of novelty value. One comment was that 'it's a great idea but only sometimes', while another was it's 'not that bad really'!

When the students were asked at VCl if they would use this method of teaching again, 58.3 per cent said yes, 25 per cent said no, 23.5 per cent said maybe, and the remainder gave no answer.

In a similar question at the end of VC3, the students were asked how they would feel about having a larger portion of their course delivered in this way. To this, 66.7 per cent gave a positive response while the remaining third replied in the negative. Despite this, when at the end of VC3 they were asked if they felt cheated or disadvantaged by being taught by VC, all but one student said no (the remaining one gave no answer).

\section{Effectiveness}

In each video-conference, the students were asked how well they learned in comparison to traditional lectures; i.e. how effective they felt this method of teaching was. The answers to this question varied as the video-conferences progressed as shown in the Table 2 below. One student commented about VC1 that 'this lecture was very well done, I learned more, but not because of the video' while another noted that it was more effective 'once you get used to it'. The novelty value, and conversely some of the antipathy to the method, seemed to have worn off with time so that by VC3, 88.9 per cent of the students felt they learned about as well in a video-conference as in a traditional lecture (see Table 2).

\begin{tabular}{lccc}
\hline$\%$ & VCl & VC2 & VC3 \\
\hline More & 20.8 & 20 & - \\
Same & 33.3 & 53.3 & 88.9 \\
Less & 33.3 & 20 & 11.1 \\
Other & 12.5 & 6.7 & - \\
\hline
\end{tabular}

Table 2: Percentages of students commenting on the effectiveness of this teaching method compared to traditional lectures (percentoges may not sum to 100 per cent due to rounding).

One student noted that it was 'difficult to answer (about effectiveness) because it depends on the lecturer and lecture content'. In effect, the video-conferencing was not thought to obscure or augment the quality of the teaching.

The students at Heriot-Watt and those at Paisley were formally assessed in written examinations on the material in these lectures. There was a choice of questions in the examination so students could have avoided this topic. However, all four students who attended all the lectures from Heriot-Watt and all the students from Paisley attempted the 
question on this topic and the average marks were equal to or slightly higher than the marks for other questions in the exams.

\section{Teaching aids}

Finally, the quality of the dynamic PowerPoint teaching aids, were generally found to be of a high quality as indicated by Table 3.

\begin{tabular}{lrrc}
\hline$\%$ & VCI & VC2 & VC3 \\
\hline Excellent & 29.2 & 66.7 & 66.7 \\
Readable & 54.2 & 33.3 & 33.3 \\
Barely readable & 12.5 & - & - \\
Unreadable & - & - & - \\
No answer & 4.2 & - & - \\
\hline
\end{tabular}

Table 3: Percentages of students commenting on the quality of the teaching aids (percentages may not sum to 100 per cent due to rounding).

\section{Cost-effectiveness?}

It is not possible, on the basis of this small experiment, to determine the cost-effectiveness of this method of teaching. It is, however, worth drawing attention to aspects that affect cost-effectiveness.

- Infrastructure costs: The video conference network used in this study is 'free at the point of use'. It is, of course, not free, but it is financed at a national level so that those who book time are not individually charged. The network used for the MANs is leased annually, not on a 'per use' basis. The greater the use, the more cost-effective this will be. Although network ports exist in each VC studio the computers and projection equipment are not yet permanently installed and must be set up for each use.

- Rehearsal: Since this was the first time any of those involved had used this technology there was a great deal of rehearsal and testing amounting to about five one-hour sessions. By the time of the lectures, however, confidence in the system was sufficiently high that we required only ten minutes prior to each lecture to set up and test the technology.

- Delivery: During a lecture it is usual for only one lecturer to be involved. During these distributed lectures a member of the course organizing staff at each site remained with the students throughout the lectures to solve any technical problems. It is advisable for one person to have this responsibility at each site and once the computer-based communication is fully integrated with the other video-conference facilities it seems likely this would become a responsibility of an 'on-call' AV technician supporting the VC suite.

- Preparation: Although the three lectures given in this experiment were already prepared and had been given several times before, the lecturer felt it necessary to improve the visual aids to compensate for the lack of physical presence. The time taken to prepare 
these visual aids was approximately four hours per lecture. The most time-consuming part was building animated diagrams that could be controlled to ensure that each frame can be guaranteed to be delivered to the remote site.

\section{Conclusions}

In spite of the relatively small number of lectures and students we can draw some significant conclusions on the technical feasibility of this approach and more tenuous conclusions about the educational value and cost-effectiveness.

- Technical feasibility: The use of shared applications through NetMeeting in support of multi-point video-conferenced teaching has been shown to be stable enough for practical use. The video-conference component used the Scottish MANs ATM network and the shared applications used the same MAN network through TCP/IP. The time taken to set up the system was minimal once the necessary tests had been completed. Consideration is now being given to making networked PCs and data projectors standard equipment in all of the Scottish (HEI) video-conferencing suites.

- Educational value: There is no evidence that delivering lectures by video-conference produces an educational benefit over traditional lectures (except perhaps that the lecturer works harder on visual aids!), nor should we expect there to be. Our primary concern is, rather, that there is no disadvantage to the students learning, or that such that exist are minimized. Students did show an increasing acceptance of the method as they became used to it and none felt they had been disadvantaged.

- Cost-effectiveness: During this experiment a significant amount of time was spent on testing and during the lectures a member of academic staff was present at each site. This suggests that any saving in staff time is marginal, resulting from only one of the staff members having preparatory work for the lecture. As the novelty wears off it is likely that less staff time at the remote sites will be required and very little rehearsal. A distinct advantage is that some students can hear lectures on topics that could not be provided in their own institutions. This is likely to be of considerable benefit in the more specialist subjects and could lead to multi-institution courses where staff at each institution contribute part of a course to the students of all participating institutions. There is also great potential for multi-point tutorials although the dynamics of distributed group discussions will require careful thought.

\section{Acknowledgements}

We would like to thank the lecturers, students and technical support staff at each of the institutions that participated in these experiments for their efforts, patience and openness to new approaches to teaching. We would also like to acknowledge the financial support of SHEFC under its use of MANs initiative. Thanks also to Prof. Gordon Peckham for allowing these lectures to be used in part of his course at Heriot-Watt University and to Brian Cameron for his photographic assistance.

\section{References}

BIC (1997), 'Blueprint for interactive classrooms', http://avc.ucd.ie/BIC/. 
Donert, K., Brady, S. and Clarkson, J. (1998), 'The design, implementation and evaluation of mass conferencing', $A L T-J, 6(1), 32-40$.

Lindsay, M. and Grant, M. (1998), 'Video conferencing over Scotland's Metropolitan Area Network', JISC Technology Applications Programme, Report 24, http://www.jtap.ac.uk/.

Pederson, G. (1996), 'Distributed electronic classrooms', http://munin/uio.no/.

MacLaren, I., Duncan, C. and Vaughan, R. (1997), 'Using the World Wide Web for remote sensing education and training', Proceedings of EARSeL Conference, Lyngby, Denmark.

Microsoft (1998), 'Microsoft NetMeeting 2.1', http://www.microsoft.comn/neeeting.

Support Initiative for Multimedia Applications, http://www.man.ac.uk/MVC//SIMA. 